\title{
Radiological and Long-Term Patient-Reported Outcome after Stabilization of Traumatic Thoraco- Lumbar Spinal Fractures using an Expandable Vertebral Body Replacement Implant.
}

\section{Siegmund Lang}

University Hospital Regensburg: Universitatsklinikum Regensburg

\section{Carsten Neumann}

University Hospital Regensburg: Universitatsklinikum Regensburg

\section{Christina Schwaiger}

University Hospital Regensburg: Universitatsklinikum Regensburg

\section{Andreas Voss}

University Hospital Regensburg: Universitatsklinikum Regensburg

\section{Volker Alt}

University Hospital Regensburg: Universitatsklinikum Regensburg

\section{Markus Loibl}

University Hospital Regensburg: Universitatsklinikum Regensburg

Maximilian Kerschbaum ( $\square$ maximilian.kerschbaum@ukr.de)

Universitatsklinikum Regensburg

\section{Research article}

Keywords: Thoraco-lumbar spinal fractures, Expandable vertebral body replacement, Posterior-anterior stabilization, Long-term radiological follow-up, Patient-reported outcome measures, Quality of Life

Posted Date: October 29th, 2020

DOl: https://doi.org/10.21203/rs.3.rs-97255/v1

License: (c) (1) This work is licensed under a Creative Commons Attribution 4.0 International License. Read Full License 


\section{Abstract}

\section{Background}

A combined posterior and anterior stabilization was found to offer a better restoration of the sagittal profile of thoracolumbar fractures in comparison to posterior-only stabilization. Data on restoring the bisegmental kyphotic endplate angle (BKA) and on patient-reported outcome measures (PROM) is sparse.

Patients and Methods

136 patients with traumatic thoraco-lumbar spinal fractures were treated with an expandable VBR implant (Obelisc ${ }^{\mathrm{TM}}$, Ulrich Medical, Germany). in our trauma department between 2001 and 2015. Radiological data acquisition was completed pre- and postoperatively, after at least six months and approximately two years after surgery. The BKA was measured at each follow-up. The patient related outcome was evaluated prospectively.

Results

117 (31 female, 86 males; age: $52.7 \pm 16.5$ years) patients were included in the study. 64 patients ( $54.7 \%$ of included patients; age: $53.2 \pm 14.8$ years) completed the PROM questionnaires and therefore were assigned to the study group. An A4 fracture was seen in 99 cases (84.6\%) and 85 (72.6\%) fractures were located at the lumbar spine. Intraoperative reduction of the BKA in 117 patients was $6.6 \pm 8.2^{\circ}(p<0.01)$. A significant loss of reduction of $2.6 \pm 4.2^{\circ}$ at the first follow-up (t1) and of $4.4 \pm 6.6^{\circ}$ at the second follow-up (t2) was measured (each $p<0.05$ ). The consolidation rate was $95.7 \%$. The total revision rate was $5.1 \%$. 64 patients ( $54.7 \%$ of included patients; age: $53.2 \pm 14.8$ years) completed the PROM questionnaires and therefore were assigned to the study group. Mean time between index surgery and completion of the PROM questionnaire was $109.4 \pm 44.6$ months. Mean ODI of was $28.4 \pm 17.6$, the mean EQ-5D VAS reached $57.9 \pm 2.5$ points. The cohort showed significantly lower SF-36 values compared to a healthy reference population (each $p<0.05$ ).

\section{Conclusion}

Treatment of traumatic thoraco-lumbar spinal fractures using an expandable VBR implant is an effective and safe procedure. A significant operative correction of the BKA could be achieved. Although the initial reconstruction of the BKA did not consist over time in the study group, satisfactory PROMs were found.

\section{Introduction}

Spinal column injuries make up a relevant share in trauma patients. The thoracic and lumbar spine is frequently affected $(1,2)$. A combined dorso-ventral stabilization has been shown to be a feasible procedure that can provide more stability for unstable traumatic vertebral fractures than a single posterior or anterior approach (3-5). Next to a posterior stabilization with an internal fixator, different methods for restoration of the anterior column have been established. Not least because tricortical bone grafts are 
associated with harvest site donor morbidity $(11,12)$, vertebral body replacement implants (VBR) have been developed over the last decades (13). Expandable implants have been proven to be an alternative to conventional cages and bone blocks (6-9). Although their effectiveness in providing primary stability has been shown, data on restoring the bi-segmental kyphotic endplate angle (BKA) is sparse. Nevertheless, the loss of ventral support and cage subsidence over time has been reported $(10,11)$. The resulting kyphotic malalignment can impair spinal function and may even result in secondary neurological complaints and disorders $(12,13)$.

This study aimed to analyze the radiological and long-term patient-reported outcome measure (PROM) after dorso-ventral treatment of traumatic thoracic and lumbar spinal fractures using an expendable VBR (Obelisc ${ }^{\mathrm{TM}}$, Ulrich Medical, Ulm, Germany).

\section{Patients And Methods}

\section{Inclusion and exclusion criteria}

Patients with traumatic thoraco-lumbar spinal fractures treated with a VBR implant in our trauma department (level 1 trauma center) between 01/2001 and 01/2015 were identified for this study. Only patients with two radiological follow-ups were included, the first conducted at least 6 months after initial surgery. Patients younger than 18 years, pathological fractures and osteoporosis were excluded. Besides patient related data (sex, age, BMI), injury mechanism, additional injuries, fracture type as well as treatment details (surgical regime; adverse events) and PROMs were collected prospectively.

\section{Ethics statement}

This study was carried out in accordance with the Declaration of Helsinki and approved by the ethics committee at the University of Regensburg in 03/2017 (Institutional Review Board Number 2017-078110). Written informed consent was obtained from all individual participants included in the study.

\section{Fracture Classification and Surgical procedure}

Fractures were classified based on plain X-rays and computer tomographic (CT) scans according the AOSpine thoracolumbar injury classification system (14). All patients were treated by one senior spine surgeon $(\mathrm{CN})$ with a single type of expandable titanium cage for vertebral body replacement (Obelisc ${ }^{\mathrm{TM}}$, Ulrich Medical, Ulm, Germany) using thoracoscopic-assisted surgery (15), a ventral/retroperitoneal approach or a dorsal approach. During discectomy of the cranial and caudal intervertebral disc the adjacent endplates were kept intact. Prior to the vertebral body replacement, dorsal instrumentation, anatomic reduction, and stabilization with a minimal invasive Schanz Screw fixateur interne were performed in prone position. The ventral stabilization was either achieved in the same session, or as part of a sequential two-step procedure.

\section{Radiological assessment}


All patients received pre- and postoperative CT scans and plain X-rays for surgery planning and verification of the correct implant position. Postoperative X-rays mark the time point t0. Additionally, plain $\mathrm{X}$-rays were made at least 6 months (t1) and 3 years (t2) after index surgery. Plain, medio-lateral X-rays were used to measure the bi-segmental kyphotic endplate angle (BKA) (Fig. 1) (16). Negative values indicate kyphosis and positive values lordosis. All measurements were performed digitally using the software package OsiriX MD (Pixmeo, Bernex, Switzerland).

\section{Quality of Life (QoL)-instruments}

The German Short-Form 36 (SF-36) (17), Oswestry Disability Index (ODI) $(18,19)$ and EuroQol in 5 Dimensions (EQ-5D) were collected prospectively. Patients were contacted by telephone and asked to participate in the study. If patients were not reachable by phone, forms were sent to the last known address. As a reference, normative data from Germany was used on the SF-36 (20). and EQ-5D (21).

\section{Statistics}

Statistical analysis was carried out using SPSS software version 24 (SPSS Inc., Chicago, Illinois). The Mann-Whitney $\mathrm{U}$ and Kruskal-Wallis tests were performed to compare categorical variables; the independent t-test was used to compare continuous variables after determining the distribution was appropriate for parametric testing. P-values $<0.05$ were considered significant. Data are presented as mean \pm standard deviation (SD) for continuous variables and as absolute and relative frequencies for categorical data.

\section{Results}

After the initial screening of the data base, $\mathrm{n}=117$ (31 females, 86 males) patients met the exclusion and inclusion criteria for radiological evaluation (Fig. 2). The mean age was $52.7 \pm 16.5$ (19-97) years. The mean time to the first radiological follow-up was $26.7 \pm 20.3(6-73)$ months and $61.0 \pm 50.7(21-213)$ to the second radiological follow-up. $\mathrm{N}=64$ patients ( 15 females, 49 males) with complete radiological follow-up completed the PROM questionnaires and therefore were included in the study group (loss to follow-up $45.3 \%$ ). The mean age of the study patients was $53.2 \pm 14.8$ years, the mean BMI was $25.9 \pm$ $3.9 \mathrm{~kg} / \mathrm{m}^{2}$. In the study group the first radiological follow-up was conducted $13.6 \pm 3.0(6-25)$ months after index surgery, the second after $38.5 \pm 42.9(21-181)$ months. The mean time between index surgery and completion of the PROM questionnaire was $109.4 \pm 44.6(26-181)$ months.

\section{Trauma Mechanism and Fracture Classification}

The most common fracture in the included patients was classified as AO Type A4 ( $n=99 ; 84.6 \%)$. AOType A3 fractures were seen in $n=10$ patients ( $8.5 \%)$ and AO-Type $A 2$ in $n=8$ patients $(6.8 \%)$. An additional $A O$ Type $C$ injury was found in $n=27(23.1 \%)$ cases. The most frequently affected vertebral body was $L 1(23.9 \%)$. In $n=32(27.4 \%)$ cases the fracture was in the thoracic spine, in $n=85(72.6 \%)$ in the lumbar spine. From those $n=75(64.1 \%)$ fractures were located at the thoracolumbal transition (Th11 
- L2). $N=102(87.2 \%)$ patients suffered from a bisegmental fracture and $n=15(13.6 \%)$ suffered from a monosegmental injury.

Preoperatively, $n=26$ (22.2\%) patients suffered neurological impairment with either a sensory deficit $n=7$ (6.0\%), or a motor deficit $\mathrm{n}=19(16.2 \%)$. In the study group $5(7.8 \%)$ patients suffered sensory deficits and $12(18.8 \%)$ patients motor deficits. $n=3(4.7 \%)$ patients could not be examined regarding the neurologic status due to initial unconsciousness.

In the study group $n=26(40.6 \%)$ patients suffered a traffic accident, $n=10(15.6 \%)$ had a fall from more than 3 meters and $n=15(23.4 \%)$ from less than 3 meters. In $n=13(20.3 \%)$ cases a not classified trauma was reported. In the study group $n=47$ patients $(73.4 \%)$ had additional injuries including additional spine injuries (Table 1).

Table 1

Additional injuries

\begin{tabular}{|llllll|}
\hline & $\mathbf{N}\left(\mathbf{N}_{\text {included }}=117\right)$ & $\mathbf{1}$ & $\mathbf{N}\left(\mathbf{N}_{\text {study }}=\mathbf{6 4}\right)$ & $\%$ & $\mathbf{P}$ \\
\hline None & $\mathbf{2 9}$ & $\mathbf{2 4 . 8}$ & $\mathbf{1 7}$ & $\mathbf{2 6 . 6}$ & \\
\hline Additional injuries & $\mathbf{8 8}$ & $\mathbf{7 5 . 2}$ & $\mathbf{4 7}$ & $\mathbf{7 3 . 4}$ & 0.758 \\
\hline Extremities & 40 & 34.2 & 16 & 25.0 & 0.027 \\
\hline Abdomen & 6 & 5.1 & 3 & 4.7 & 0.831 \\
\hline Thorax & 35 & 29.9 & 20 & 31.3 & 0.682 \\
\hline Pelvis & 9 & 7.7 & 3 & 4.7 & 0.192 \\
\hline Spine & 43 & 36.8 & 22 & 34.4 & 0.613 \\
\hline Head/Face & 7 & 6.0 & 5 & 7.8 & 0.349 \\
\hline
\end{tabular}

Table 1: Additional injuries: Comparison between included patients $(n=117)$ and the study group $(n=64)$. There was no statistically significant difference detected between the included patients and the study group.

\section{Treatment}

All patients, included in this study, were treated operatively with a VBR device. 92 patients (78.6\%) received bisgemental instrumentation. Posterior decompression was performed in $n=58(49.6 \%)$ patients, posterior fusion in $n=59(50.4 \%)$ patients. In the study group a thoracoscopic approach was chosen in 25 patients. In $n=37$ patients a ventral, retroperitoneal approach was performed. In two cases the VBR was implanted through a dorsal approach. Between the groups no statistically significant difference in the surgery duration was detected $(p=0.51)$. All patients received posterior instrumentation. In the study group posterior decompression was performed in $n=15(23.4 \%)$ patients and posterior fusion in $n=43(67.2 \%)$ patients. All patients in the study group received a VBR (Obelisc ${ }^{\mathrm{TM}}$, Ulrich Medical, 
Ulm, Germany). In n= $7(10.9 \%)$ cases an additional anterior angular stable plate system (goldengate ${ }^{\circ}$, ulrich medical, Ulm, Germany) was used.

\section{Adverse events}

The overall complication rate was 16.2\% (19/117): In 6 cases patients developed a surgical site infection, 8 patients suffered prolonged wound healing or a liquor fistula and in 5 cases implant loosening or secondary dislocation was recorded. The revision rate was $5.1 \%$ and all revisions $(n=6)$ occurred within the study group (9.4\%): All patients with infection $(n=2)$, impaired wound healing $(n=2)$ and Screw or Golden Gate malposition $(n=2)$ had to be revised. No statistically significant difference in the occurrence of complications was detected between the different surgical approaches was seen $(p=0.74)$. Complications were recorded in 15 cases $(23.4 \%)$ of the study group. No in-hospital deaths were documented.

\section{Radiological Outcome BKA included patients}

Within the entire collective patients $(n=117)$, when all fracture locations (thoracic and lumbar spine) were subsumed, a mean preoperative BKA of $-5.5 \pm 3.4^{\circ}$ was found. Although the kyphosis angle was significantly reduced by $6.6 \pm 8.2^{\circ}$ (t0) by surgery $(p<0.01)$, a significant loss of reduction of $2.6 \pm 4.2^{\circ}$ at the first follow-up (t1) and of $4.4 \pm 6.6^{\circ}$ at the second follow-up (t2) was measured (each $p<0.05$ ). Figure 3 illustrates the development of the BKA at the thoracic (A) and the lumbar (B) spine. The fusion rate in the included patients was $95.7 \%(112 / 117)$ at the second radiological follow-up.

\section{BKA study group}

Table 2 displays the changes in the BKA of the matched pairs of thoracic and lumbar fractures of the study group $(n=64)$, respectively. At the thoraco-lumbal transition surgery changed the BKA significantly by $5.0 \pm 7.9^{\circ}(p<0.05)$. Loss of reduction was statistically significant with $2.7 \pm 3.5^{\circ}(p<0.05)$ until the first follow-up and with $4.0 \pm 5.0^{\circ}(p<0.01)$ until the second follow-up. In the study group complete fusion was seen in 45 patients $(70.3 \%)$ after the second follow-up (t2; $38.5 \pm 42.9$ months). Dorsal stabilization remained in $n=56$ patients $(87.5 \%)$ and was removed in 8 patients (12.5\%) after $13.1 \pm 7.2$ months. 
Table 2

Changes in the bisegmental kyphotic endplate angle

\begin{tabular}{|lllll|}
\hline & Time Points & Mean \pm SD $\left[^{\circ}\right]$ & Range $\left.~^{\circ}\right]$ & p \\
\hline Thoracic spine & Reduction & $-7.3 \pm 7.4$ & -26.7 to 0.67 & $<0.01$ \\
& t0 vs t1 & $3.2 \pm 4.1$ & -0.5 to 10.8 & $<0.05$ \\
& t0 vs t2 & $3.4 \pm 4.3$ & -0.17 to 12.44 & $<0.05$ \\
\hline \multirow{2}{*}{ Lumbar spine } & Reduction & $-6.2 \pm 8.6$ & -5.9 to 0.3 & $<0.01$ \\
\hline & t0 vs t1 & $1.5 \pm 2.4$ & -0.8 to 8.4 & $<0.01$ \\
\hline & t0 vs t2 & $3.4 \pm 4.4$ & -0.7 to 16.8 & $<0.01$ \\
\hline
\end{tabular}

Table 2: Changes in the BKA between preoperative and postoperative (Reduction) and the different time points (t0, $\mathrm{t} 1, \mathrm{t} 2)$ in the follow-up. P-Values in bold indicate significant changes.

\section{Patient-reported outcome:}

EQ-5D VAS reached $57.9 \pm 2.5$ points. No significant differences between the location of the fracture (thoracic/lumbar) was found ( $p=0.52$ ). Figure 4 displays the subdimensions of EQ-5D. Patients with initial motor deficit $(n=12)$ reported a significant lower EQ-5D Index $(0.3 \pm 0.3)$ than patients with only sensory deficit or without neurological impairment $(0.8 \pm 0.2)(p<0.05)$.

The mean ODI of the total cohort was $28.4 \pm 17.6 . \mathrm{N}=20$ (31.3\%) patients reported minimal, $\mathrm{n}=28$ (43.8\%) moderate and $n=15(23.4 \%)$ severe disability. One patient (1.6\%) reported crippling back pain and no patient $(0 \%)$ suffered exacerbated back pain or was bed-bound. There was no significant difference in the distribution of the scorings between thoracic and lumbar fractures $(p=0.82)$ (Fig. 5).

Table 3 shows the results of the 8 main SF-36 items of the study group in comparison to a healthy reference population (20). The cohort showed significant lower values compared to the healthy population for each item (each $\mathrm{p}<0.05$ ). Comparing thoracic and lumbar location of the treated fracture, no significant difference between the single items was found $(p>0.05)$. 
Table 3

Main SF-36 items

\begin{tabular}{|c|c|c|c|}
\hline & $\begin{array}{l}\text { German reference population } \\
2013\end{array}$ & $\begin{array}{l}\text { Study } \\
\text { group }\end{array}$ & Significant differences \\
\hline Physical functioning & $85.2(84.0-86.4)$ & $\begin{array}{l}49.37 \pm \\
28.67\end{array}$ & $\mathrm{p}<0.05$ \\
\hline Role physical & $80.1(78.7-81.6)$ & $\begin{array}{l}40.08 \pm \\
45.69\end{array}$ & $\mathrm{p}<0.05$ \\
\hline Role emotional & $84.7(83.3-86.1)$ & $\begin{array}{l}51.85 \pm \\
46.29\end{array}$ & $\mathrm{p}<0.05$ \\
\hline Energy & $61.8(60.6-62.9)$ & $\begin{array}{l}46.39 \pm \\
19.09\end{array}$ & $p<0.05$ \\
\hline $\begin{array}{l}\text { Emotional Well- } \\
\text { Being }\end{array}$ & $72.0(70.9-73.1)$ & $\begin{array}{l}62.97 \pm \\
17.10\end{array}$ & $\mathrm{p}<0.05$ \\
\hline Social functioning & $84.7(70.9-73.1)$ & $\begin{array}{l}70.12 \pm \\
24.96\end{array}$ & $\mathrm{p}<0.05$ \\
\hline Bodily Pain & $72.0(70.4-73.6)$ & $\begin{array}{l}56.34 \pm \\
25.78\end{array}$ & $p<0.05$ \\
\hline General health & $67.6(66.5-68.7)$ & $\begin{array}{l}51.02 \pm \\
21.63\end{array}$ & $\mathrm{p}<0.05$ \\
\hline
\end{tabular}

Table 3. The eight main SF-36 items in comparison to the normative data of the German population (20). The reference values are presented as mean with $95 \%$ confident interval. There remains statistically significant difference between the study group and a healthy German population in all main items.

To assess the influence of loss of reduction on the PROM we defined relevant loss of reduction as a change of the BKA between the postoperative X-ray and the second follow-up by $\pm 3^{\circ}$. In $N=12(18.8 \%)$ cases a relevant loss of reduction of $8.3 \pm 4.0^{\circ}$ at mean was found. In all other cases the mean change in BKA was $0.9 \pm 1.1^{\circ}$.

Between the two groups with and without a relevant loss of reduction no statistically significant differences in all SF-36 items, ODI and EQ-5D parameters were detected (all $p>0.05$ ).

\section{Discussion}

The use of an expandable vertebral body replacement implant proves to be a safe procedure with only few implant-associated adverse events and a revision rate of $5.1 \%$ in the current study population. Bony consolidation was seen in $95.7 \%$ of patients, in concordance with the existing literature $(7,22)$. All patients underwent surgery with insertion of a single type of expandable vertebral body replacement implant and implant dislocation, or loosening was observed only in $n=5$ patients. Unlike other studies, 
that included heterogenous indications and used different implants, the current homogenous cohort contains only trauma patients with a 9-years PROM follow-up at average.

The presence of additional injuries must be discussed as a possible confounder of the PROM. Many patients (73.4\%) in the study group suffered from additional injuries of one or more body regions. In this study no correlation between additional injuries and PROM was detected. Patients with initial motor deficits showed significant worse outcomes in the SF-36 dimension "physical function" and in the EQ-5D index. Similarly, McLain et al. documented in a 5-year follow-up after spinal injuries of 62 severely injured patients treated with segmental spinal instrumentation, that a neurological injury had a greater impact on functional outcome than other variables (12).

The results of this study show a lower patient-related life quality especially in the SF-36 compared to an age-matched reference population (20). However, regardless of the high number of additional injuries and neurological impairments the overall functional outcomes were satisfactory. The EQ-5D subdimensions reveal the distribution of cases with only a few "poor" results and mostly "moderate" or even "excellent" results. Regarding the ODI outcome only one patient reported crippling back pain and no patient suffered exacerbated back pain or was bed-bound. The mean ODI of the total cohort was 28.4 points indicating mild impairment. Contrary to this finding, Kumar et al. reported a mean ODI score of 14 points 18 months after an open surgery procedure for thoracolumbar burst fractures (23). However, in their collective there was no evidence of neurological compromise and no additional injuries, therefore representing a different collective with less severe injured patients. In line with our findings, Kreinest et al. found most patients to be satisfied, 3 years after implantation of a hydraulic expandable VBR following traumatic thoracic and lumbar vertebral fractures (8). The mean rating of the VAS Spine score of their study population was 65.2 \pm 23.1 , which was found to be comparable to the rating of 58.4 from the German Spine Fracture Registry for operatively treated patients after spine fractures (4). Like our findings, they saw a significant reduction of functional outcome scores in their study cohort when compared to healthy subjects (8). Indeed, other study-groups like Spiegl et al. achieved better VAS Scores with a thoracoscopic procedure (24), but in the current study we could not identify a significant influence of the surgical approach or other surgeryrelated parameters on the PROM.

In our study group all patients were treated with a combined anterior and posterior strategy and in only a few cases $(12.5 \%)$ the dorsal instrumentation was removed during the follow-up period. The data found in literature does not suggest any difference in PROM depending on ventral or dorsal or combined surgery strategies of traumatic fractures of the thoracic and lumbar spinal column $(4,25)$. In a prospective cohort study, examining the six-year outcome of thoracoscopic ventral spondylodesis after unstable incomplete cranial burst fractures of the thoracolumbar junction Spiegl et al. compared ventral only and dorsoventral treatment strategies and found a higher operative correction in dorso-ventrally treated patients (24). They also reported that a high percentage of the operative correction was lost after six years, which is in line with our findings. Several authors claim an association between kyphotic malalignment and functional outcome $(26,27)$. In contrast, other studies did not find a significant correlation between radiological and functional outcomes $(4,28)$. 
We showed a reduction of the BKA in 117 patients of $7.3^{\circ}$ at the thoracic and of $6.7^{\circ}$ at the lumbar spine and similar values were found in the study group. This is in the range of the reduction potential of posttraumatic kyphotic deformity, reported by the Spine Study Group of the German Trauma Association of 5.7 and $5.1^{\circ}$ for the bi-segmental wedge angle using various implants with an open approach in the thoracic and lumbar spine, respectively (4). In 2015 our study group conducted a clinical and radiological one-year follow-up assessment of 26 patient with fractures of the thoracic and lumbar spine treated with bi-segmental dorsal instrumentation with a minimal-invasive transpedicular Schanz Screw system (29). For additional ventral reconstruction different methods were performed and an intraoperative reduction of the BKA by $11.5^{\circ}$ among all patients could be achieved. $5.8^{\circ}$ loss of reduction were seen after six weeks. At the one-year follow-up a loss of reduction of $4.9^{\circ}$ after dorsoventral stabilization was reported. Similarly, the current study reveals a loss of reduction of $6.0^{\circ}$ at the lumbar spine after approximately 3 years. At the thoracic spine, no significant loss of reduction was found in 117 patients. In the study group of 64 patients a significant loss of reduction was seen during the follow-up, at the thoracic and the lumbar spine and at fractures of the thoraco-lumbar junction. However, to difference in the PROMs of patients with a relevant loss of reduction of minimum $3.0^{\circ}$ and patients without a relevant loss of reduction was observed. It is worth noting, that the comparison between the pre-and postoperative angel includes a possible influence of patients positioning, as the preoperative CT scan was assessed in a supine position and postoperative and follow-up X-rays were taken with the patient standing up-right (30).

Schnake et al. reported an average postoperative loss of correction of $2.4^{\circ}$ due to minimal subsidence of the cages in a five-year clinical and radiological follow-up of 54 patients that had received combined anteroposterior stabilization of thoracolumbar fractures (7). The cage subsidence has been reported and was interpreted as a "settling down" of the anteroposterior construction, that appeared mainly in the first postoperative year (7). Although not examined in detail, cage subsidence may have also played a role in the loss of reduction in our study.

\section{Conclusion}

Stabilization of traumatic thoraco-lumbar spinal fractures using an expandable VBR implant is an effective and safe procedure. A significant operative correction of the BKA could be achieved initially at both the thoracic and lumbar spine. Although the initial reconstruction of the BKA did not consist over time in the study group, satisfactory PROMs were found. Nevertheless, the level of the healthy reference population could not be reached.

\section{List Of Abbreviations}

BKA Bisegmental kyphotic endplate angle

BMI Body mass index

CT Computed tomography 
EQ-5D EuroQol in 5 Dimensions

ICBG Iliac crest bone graft

ODI Oswestry Disability Index

PROM Patient reported outcome measure

QoL Quality of Life

SD Standard deviation

SF-36 Short Form 36

VAS Visual analogue scale

VBR Vertebral Body replacement

\section{Declarations}

\section{Research Ethics Committee}

This study was carried out in accordance with the Declaration of Helsinki and approved by the ethics committee at the University of Regensburg in 03/2017: Institutional Review Board Number 2017-0781-10. Written informed consent was obtained from all patients included in the study.

\section{Consent for publication}

This manuscript does not contain any individual person's data in any form.

\section{Availability of data and materials}

The datasets used and/or analyzed during the current study are available from the corresponding author on reasonable request.

\section{Competing interests}

Financial and personal relationships: The Author Carsten Neumann is a consultant for Ulrich medical Germany.

Potential competing interests: None.

\section{Funding}

No funding has been received for this study.

\section{Authors' contributions}


SL helped to design the study, conduct the study, analyze the data, and write the manuscript.

SL has seen the original study data, reviewed the analysis of the data, approved the final manuscript, and is the author responsible for archiving the study files.

CN helped to conduct the study.

$\mathrm{CN}$ has seen the original study data, reviewed the analysis of the data, and approved the final manuscript.

CS helped to conduct the study.

CS has seen the original study data, reviewed the analysis of the data, and approved the final manuscript.

AV helped to conduct the study.

AV has seen the original study data, reviewed the analysis of the data, and approved the final manuscript.

VA helped to conduct the study.

VA has seen the original study data, reviewed the analysis of the data, and approved the final manuscript.

ML helped to conduct the study.

ML has seen the original study data, reviewed the analysis of the data, and approved the final manuscript.

MK helped to design the study, analyze the data, and write the manuscript. He is the corresponding author of this manuscript.

MK has seen the original study data, reviewed the analysis of the data, and approved the final manuscript.

\section{Acknowledgements}

Not applicable.

\section{References}

1. Bühren V. [Injuries to the thoracic and lumbar spine]. Unfallchirurg. 2003;106(1):55-68; quiz 68-9.

2. DeWald RL. Burst fractures of the thoracic and lumbar spine. Clin Orthop. 1984;(189):150-61.

3. Wilke H-J, Kemmerich V, Claes LE, Arand M, et al. Combined anteroposterior spinal fixation provides superior stabilisation to a single anterior or posterior procedure. J Bone Joint Surg Br. 2001;83B(4):609-17.

4. Reinhold M, Knop C, Beisse R, Audigé L, Kandziora F, Pizanis A, et al. [Operative treatment of traumatic fractures of the thoracic and lumbar spinal column: Part III: Follow up data]. Unfallchirurg. 
2009;112(3):294-316.

5. Kim B-G, Dan J-M, Shin D-E. Treatment of Thoracolumbar Fracture. Asian Spine J. 2015;9(1):133-46.

6. Reinhold M, Schmölz W, Canto F, Krappinger D, Blauth M, Knop C, et al. Ein verbessertes Wirbelkörperersatzimplantat für die thorakolumbale Wirbelsäule: Biomechanischer In-vitro-Test an humanen Lendenwirbelkörpern. Unfallchirurg. 2007;110(4):327-33.

7. Schnake KJ, Stavridis SI, Kandziora F. Five-year clinical and radiological results of combined anteroposterior stabilization of thoracolumbar fractures. J Neurosurg Spine. 2014;20(5):497-504.

8. Kreinest M, SchmahI D, Grützner PA, Matschke S. Radiological Results and Clinical Patient Outcome After Implantation of a Hydraulic Expandable Vertebral Body Replacement following Traumatic Vertebral Fractures in the Thoracic and Lumbar Spine: A 3-Year Follow-Up. Spine. 15. 2017;42(8):E482-9.

9. Knop C, Blauth M, Bühren V, Arand M, Egbers HJ, Hax PM, et al. [Surgical treatment of injuries of the thoracolumbar transition-3: Follow-up examination. Results of a prospective multi-center study by the "Spinal" Study Group of the German Society of Trauma Surgery]. Unfallchirurg. 2001;104(7):583-600.

10. Schmieder K, Wolzik-Grossmann M, Pechlivanis I, Engelhardt M, Scholz M, Harders A. Subsidence of the wing titanium cage after anterior cervical interbody fusion: 2-year follow-up study. J Neurosurg Spine. 2006;4(6):447-53.

11. Briem D, Linhart W, Lehmann W, Bullinger M, Schoder V, Meenen NM, et al. [Investigation of the health-related quality of life after a dorso ventral stabilization of the thoracolumbar junction]. Unfallchirurg. 2003;106(8):625-32.

12. McLain RF. Functional outcomes after surgery for spinal fractures: return to work and activity. Spine. 15. 2004;29(4):470-7; discussion Z6.

13. Gertzbein SD. Neurologic deterioration in patients with thoracic and lumbar fractures after admission to the hospital. Spine. 1. 1994;19(15):1723-5.

14. Vaccaro AR, Oner C, Kepler CK, Dvorak M, Schnake K, Bellabarba C, et al. AOSpine thoracolumbar spine injury classification system: fracture description, neurological status, and key modifiers. Spine. 1. 2013;38(23):2028-37.

15. Ringel F, Stoffel M, Stüer C, Totzek S, Meyer B. Endoscopy-assisted approaches for anterior column reconstruction after pedicle screw fixation of acute traumatic thoracic and lumbar fractures. Neurosurgery. 2008;62(5 Suppl 2):ONS445-452; discussion ONS452-453.

16. Keynan O, Fisher CG, Vaccaro A, Fehlings MG, Oner FC, Dietz J, et al. Radiographic measurement parameters in thoracolumbar fractures: a systematic review and consensus statement of the spine trauma study group. Spine. 1. 2006;31(5):E156-165.

17. Bullinger M. German translation and psychometric testing of the SF-36 Health Survey: preliminary results from the IQOLA Project. International Quality of Life Assessment. Soc Sci Med 1982. 1995;41(10):1359-66. 
18. Roland M, Fairbank J. The Roland-Morris Disability Questionnaire and the Oswestry Disability Questionnaire. Spine. 15. 2000;25(24):3115-24.

19. Fairbank JC, Couper J, Davies JB, O'Brien JP. The Oswestry low back pain disability questionnaire. Physiotherapy. 1980;66(8):271-3.

20. Ellert U, Kurth BM. [Health related quality of life in adults in Germany: results of the German Health Interview and Examination Survey for Adults (DEGS1)]. Bundesgesundheitsblatt Gesundheitsforschung Gesundheitsschutz. 2013;56(5-6):643-9.

21. Hinz A, Klaiberg A, Brähler E, König H-H.. [The Quality of Life Questionnaire EQ-5D: modelling and norm values for the general population]. Psychother Psychosom Med Psychol. 2006;56(2):42-8.

22. Heary RF, Kheterpal A, Mammis A, Kumar S.. Stackable carbon fiber cages for thoracolumbar interbody fusion after corpectomy: long-term outcome analysis. Neurosurgery. 2011;68(3):810-8; discussion 818-819.

23. Kumar A, Aujla R, Lee C. The management of thoracolumbar burst fractures: a prospective study between conservative management, traditional open spinal surgery and minimally interventional spinal surgery. SpringerPlus. 2015.4:204

24. Spiegl U, Hauck S, Merkel P, Bühren V, Gonschorek O. Six-year outcome of thoracoscopic ventral spondylodesis after unstable incomplete cranial burst fractures of the thoracolumbar junction: ventral versus dorso-ventral strategy. Int Orthop. 2013;37(6):1113-20.

25. Sasso RC, Renkens K, Hanson D, Reilly T, McGuire RA. Unstable thoracolumbar burst fractures: anterior-only versus short-segment posterior fixation. J Spinal Disord Tech. 2006;19(4):242-8.

26. Phan K, Nazareth A, Hussain AK, Dmytriw AA, Nambiar M, Nguyen D, et al. Relationship between sagittal balance and adjacent segment disease in surgical treatment of degenerative lumbar spine disease: meta-analysis and implications for choice of fusion technique. Eur Spine $\mathrm{J}$ Off Publ Eur Spine Soc Eur Spinal Deform Soc Eur Sect Cerv Spine Res Soc. 2018;27(8):1981-91.

27. Domenicucci M, Preite R, Ramieri A, Ciappetta P, Delfini R, Romanini L. Thoracolumbar fractures without neurosurgical involvement: surgical or conservative treatment? J Neurosurg Sci. 1996;40(1):1-10.

28. Wood K, Buttermann G, Butterman G, Mehbod A, Garvey T, Jhanjee R, et al. Operative compared with nonoperative treatment of a thoracolumbar burst fracture without neurological deficit. A prospective, randomized study. J Bone Joint Surg Am. 2003;85(5):773-81.

29. Loibl M, Korsun M, Reiss J, Gueorguiev B, Nerlich M, Neumann C, et al. Spinal fracture reduction with a minimal-invasive transpedicular Schanz Screw system: clinical and radiological one-year followup. Injury 2015;46 Suppl 4:S75-82.

30. Lee E, Woong Ko C, Woo Suh, Kumar S, II kyu K, Yang J-H. The effect of age on sagittal plane profile of the lumbar spine according to standing, supine, and various sitting positions. J Orthop Surg. 27. 2014;9:11.

\section{Figures}




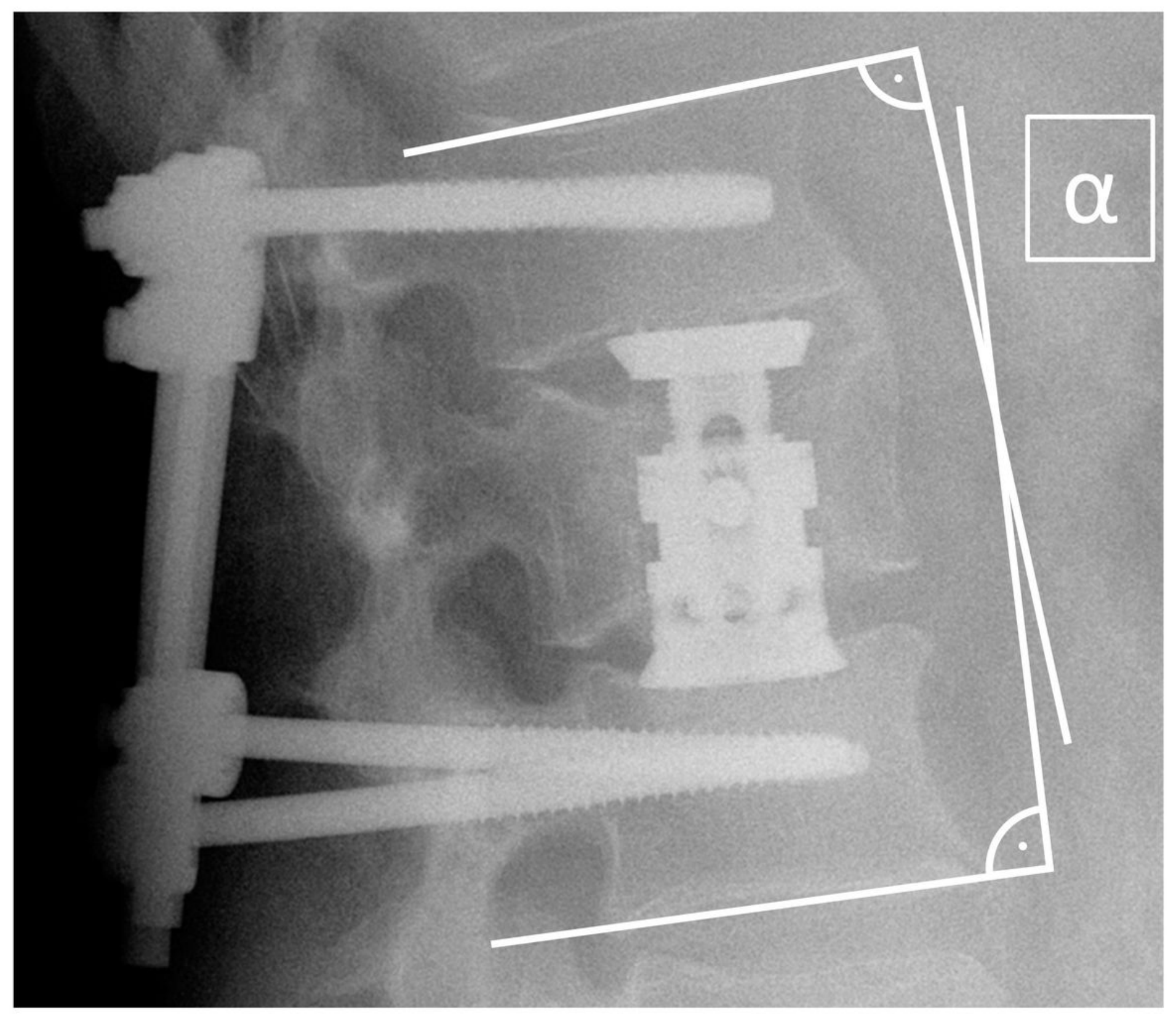

Figure 1

Measurement of the bisegmental kyphotic endplate angle a between a line drawn parallel to the superior endplate of one vertebra above the fracture, and a line drawn parallel to the inferior endplate of the vertebra below the fracture. 


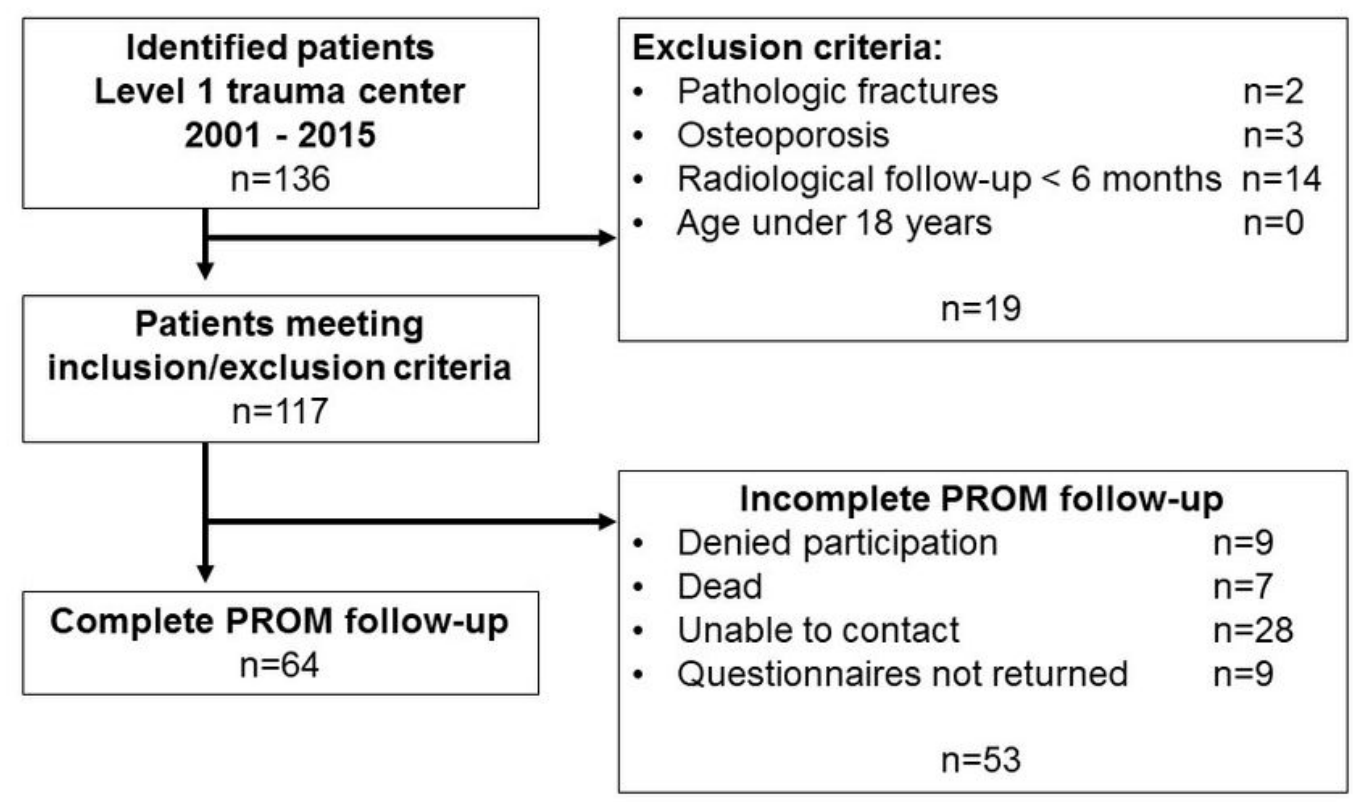

\section{Figure 2}

Flowchart: From 136 patients treated between 2001 and $2015 \mathrm{n}=117$ met the inclusion and exclusion criteria. $\mathrm{N}=64$ patients completed the PROM follow-up and therefore were assigned to the study group. 

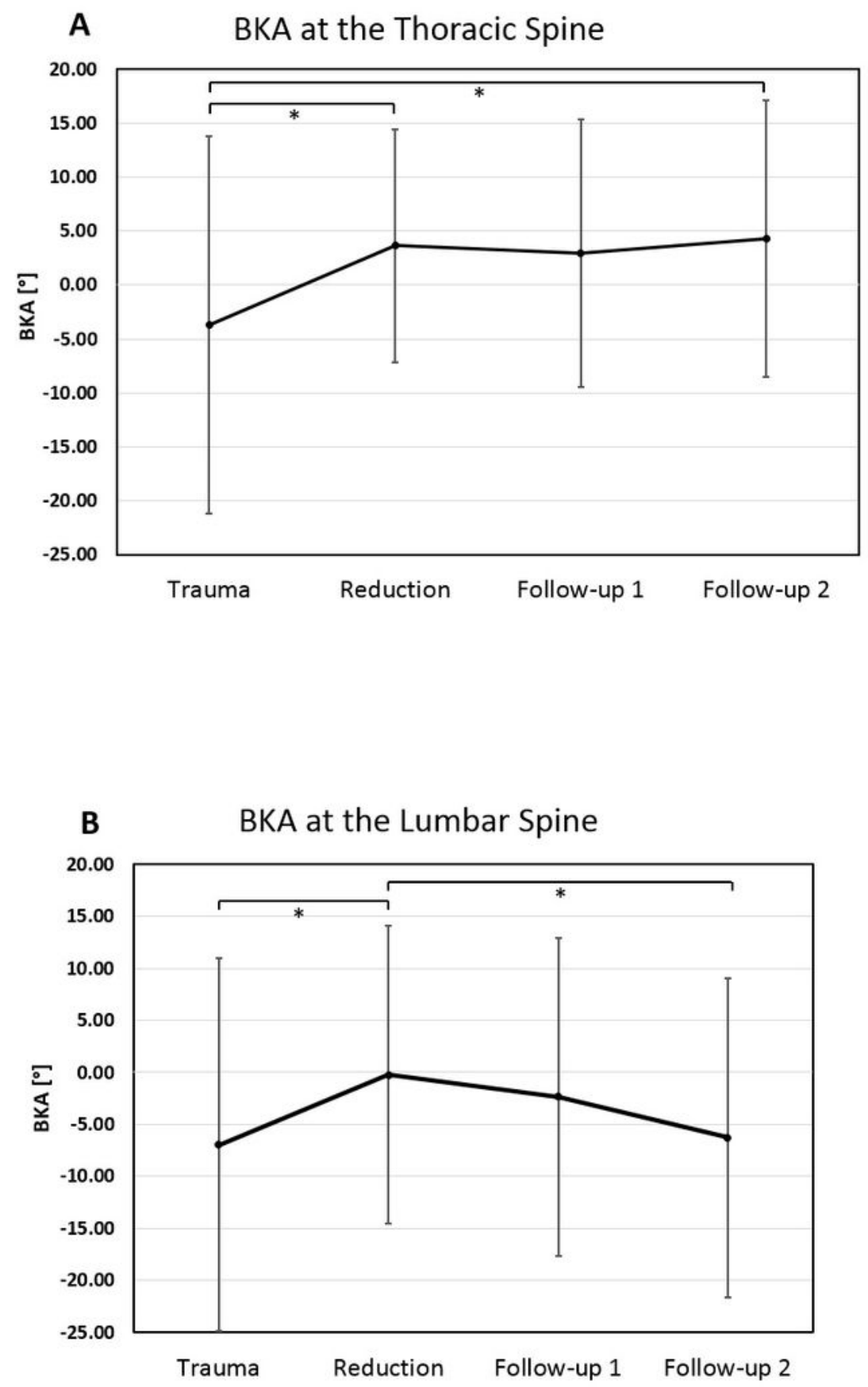

\section{Figure 3}

Visualization of the changes in the BKA (117 included patients) of the thoracic and lumbar spine. At the thoracic spine $(A)$ a mean preoperative BKA of $-3.7^{\circ} \pm 17.5^{\circ}$ could be significantly reduced by $7.3^{\circ}$ and no loss of reduction was observed during the follow-up. At the lumbar spine, a mean preoperative BKA $-6.9^{\circ}$ $\pm 17.9^{\circ}$ could be significantly reduced by $6.7^{\circ}$ and a significant loss of reduction during the follow-up by $-6.0^{\circ}$ was observed. * indicating $\mathrm{p}<0.05$. 


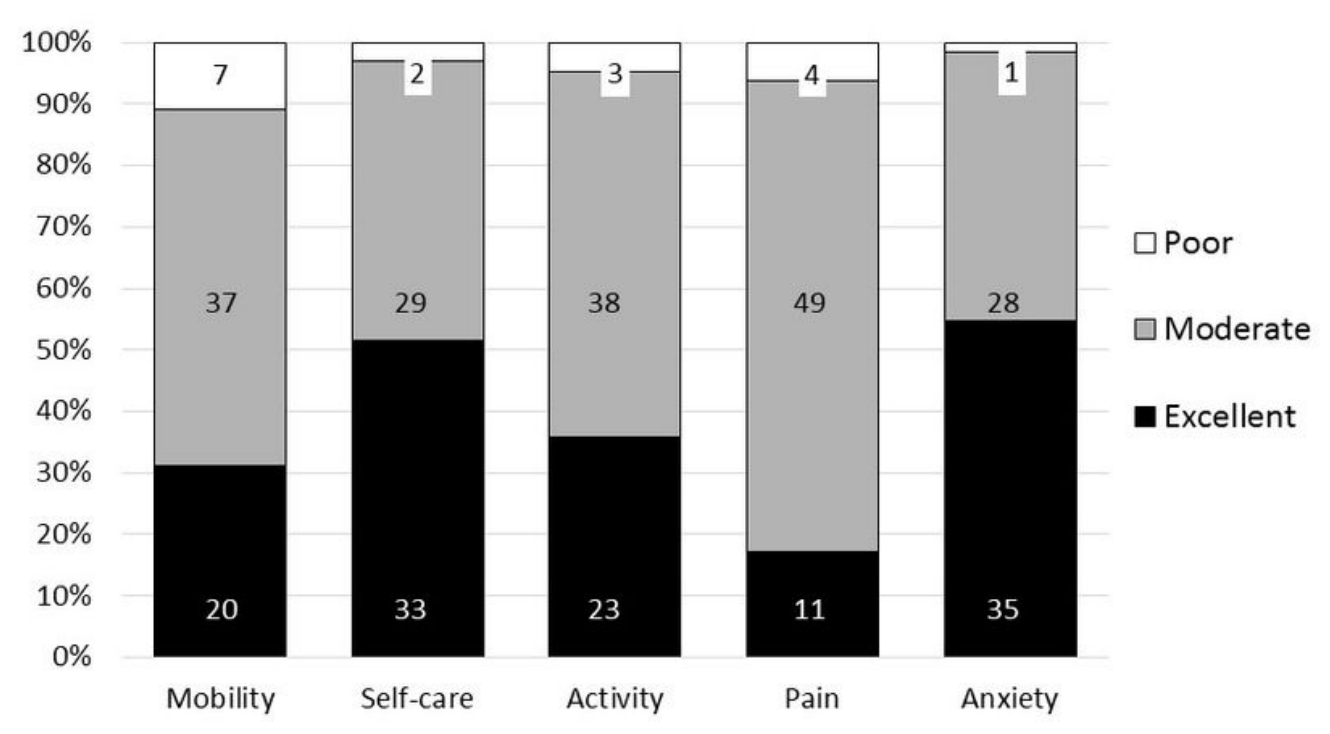

Figure 4

Subdimension of EQ-5D The five subdimension of EQ-5D. The columns represent $100 \%$ of patients and the absolute numbers in the columns show the distribution of outcomes in "Poor", "Moderate" and "Excellent". 


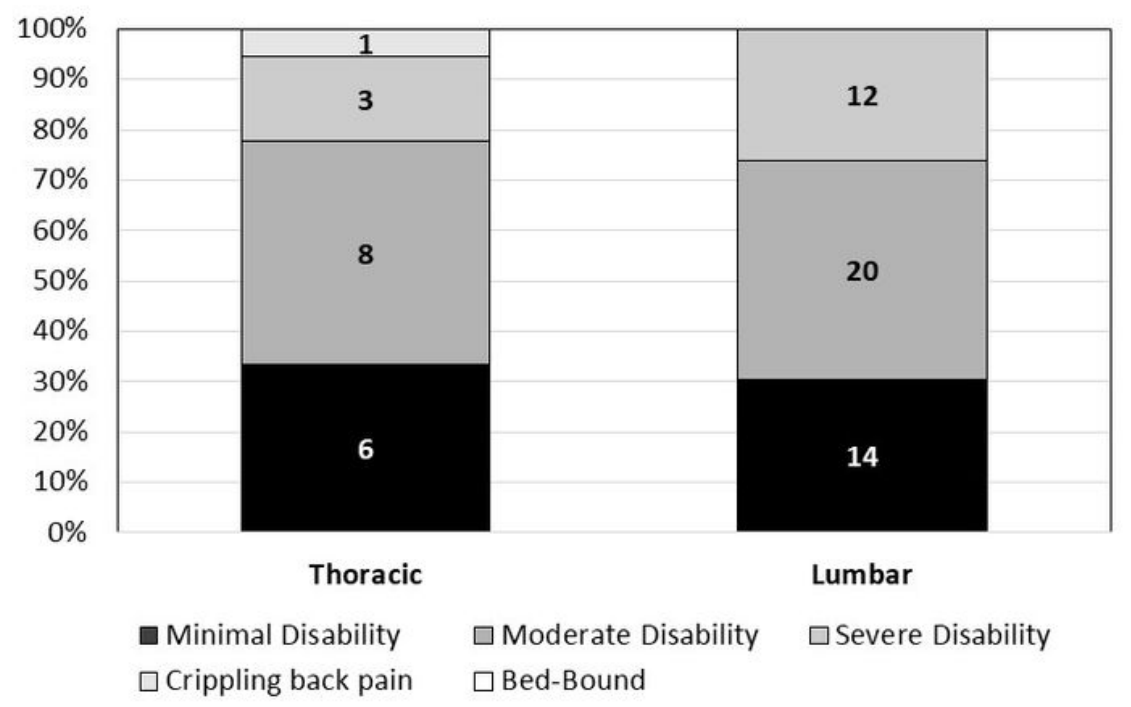

\section{Figure 5}

ODI scoring The five categories of disability in ODI scoring and the distribution of patients with surgery at the thoracic and the lumbar spine. The columns represent $100 \%$ of patients and the absolute numbers of cases are given within the respective category. 